\title{
PROFILE OF PATIENTS PRESENTING WITH ASTHMA IN PEDIATRIC OPD OF KATHMANDU MEDICAL COLLEGE
}

Bhatta $A^{1^{*}}$

\section{Affiliation}

1. Lecturer, Department of Paediatrics, Kathmandu Medical College Teaching Hospital, Nepal

\section{ARTICLE INFO}

\section{Article History}

Received : 08July, 2018

Accepted : 18 August, 2018

Published : 31 August, 2018

(C) Authors retain copyright and grant the journal right of first publication with the work simultaneously licensed under Creative Commons Attribution License CC - BY 4.0 that allows others to share the work with an acknowledgment of the work's authorship and initial publication in this journal.

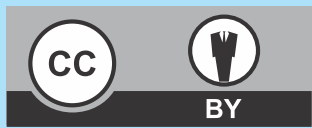

ORA 79

DOI: http://dx.doi.org/10.3126/bjhs.v3i2.20965

\section{* Corresponding Author}

Dr Anwesh Bhatta Lecturer

Kathmandu Medical College, Sinamangal, Kathmandu Email: anwesh.bhatta@gmail.com ORCID: https://orcid.org/0000-0002-6100-545X

\section{Citation}

Bhatta A. Profile of Patients Presenting with Asthma in Pediatric OPD of Kathmandu Medical College. BJHS 2018;3(2)6: 480-483.

\section{ABSTRACT}

\section{Introduction}

Asthma is the most common chronic disorder of childhood accounting for a significant proportion of childhood disability. Although asthma has been known to be a result of complex interplay between genetic and environmental factors, other added factors have been studied.

\section{Objective}

This study was conducted to assess the patient characteristics and different risk factors in children with asthma.

\section{Methodology}

The study was a cross-sectional study carried out at Kathmandu Medical College for duration of six months. Patients were labeled as asthma as per the diagnosis guideline of Global Initiative for Asthma (GINA) 2016. After the diagnosis of asthma, patient and their caregivers sat for a face to face interview and a detailed proforma was filled up. Data was then entered in SPSS 20 and descriptive analysis was done to analyze the results.

\section{Results}

A total of 69 patients labeled with the diagnosis of asthma were enrolled during the study period. The mean age of the enrolled patients was $6.44( \pm 3.36)$ years. Male outnumbered the females $(17: 8)$. The study showed $45(65.2 \%)$ of the patients had a physician diagnosed allergic rhinitis while only around $5 \%$ had atopic dermatitis. Around $52.2 \%$ of the patients had a family history of atopy. Most of the patients (75.4\%) enrolled in the study were labeled as mild persistent asthma followed by intermittent asthma in $18.8 \%$ and moderate persistent asthma in $5.8 \%$.

\section{Conclusion}

The study found asthma to be more prevalent in male population while mild persistent asthma was the most common severity present in the population. The most frequent risk factor for asthma found in the current study was physician diagnosed allergic rhinitis.

\section{KEYWORDS}

Asthma; pediatric asthma 


\section{INTRODUCTION}

Asthma is a chronic inflammatory disorder. The International Consensus Report on the Diagnosis and Treatment of Asthma defines asthma as 'a chronic inflammatory disorder of the airways in which many cells play a role, including mast cells and eosinophils. In susceptible individuals, this inflammation causes symptoms that are usually associated with widespread but variable airflow obstruction that is often reversible, either spontaneously or with treatment, and causes an associated increase in airway responsiveness to a variety of stimuli'. ${ }^{1}$ It is characterized by 3 Rs, i.e. reversibility, rhythmicity and reactivity. Asthma is a disorder characterized by increase reactivity of the airway giving rise to inflammation and bronchospasm.

The prevalence of asthma has been increasing worldwide. Children comprise a major portion of asthma patient across the globe. In fact, asthma is the most common chronic respiratory illness in children worldwide. ${ }^{2}$ The prevalence of asthma has been increasing in the developing countries while in the developed countries the prevalence is found to be stable. ${ }^{3}$ Since the prevalence is higher in children and asthma is a chronic condition, it causes considerable stress to the caregivers and parents of the diseased children. Moreover, for this same reason, it becomes truly important to study the factors affecting the development and progression of this disease.

Multiple studies have been carried out to assess different factors associated with development of asthma. Studies worldwide have shown prematurity, low birth weight, family history of asthma, passive smoking, history of allergic rhinitis, atopic dermatitis, exposure to pets, cockroaches and mites etc to be associated with development of asthma. ${ }^{4}$ Very few studies were found to have been done in Nepal regarding the risk factors and demographic profile of children with asthma. This study was conducted to assess the demographical profile as well as risk factors present in patients with asthma presenting in Pediatric outpatient department of Kathmandu Medical College.

\section{METHODOLOGY}

Descriptive, cross-sectional study design was used to carry out the study. The data was collected at the Pediatrics outpatient department of Kathmandu Medical College and Teaching Hospital for a duration of six months between March 2017 and August 2017. Hence, the total sample size was 69 asthma patients.

Purposive sampling technique was used to collect data from asthma patients. Patients were labeled as asthma as per the diagnosis guidelines of Global Initiative for Asthma (GINA) 2016. The best peak expiratory flow (PEF) in children more than six years of age was recorded with the help of a peak flow meter. Increase of more than $20 \%$ PEF after nebulization with salbutamol was regarded as consistent with the diagnosis of asthma. Due to difficulty in diagnosis of asthma in children less than five years, probability based diagnosis of asthma was made as per GINA guidelines.
Following the diagnosis of asthma, face to face interview was conducted with the parents/ caregivers of the asthma patients in the Pediatric OPD. Also, the patient was examined clinically and their height, weight, vital signs and peak flow rate were taken and a detailed proforma was filled up. Body mass index was later calculated from height and weight. In patients more than six years old, the PEF was taken again after giving salbutamol nebulization as per GINA guidelines to confirm the diagnosis of asthma. The same instruments were used for all patients and the instruments were checked for proper calibration each time before taking the measurements. The proforma was devised by the researcher himself with extensive literature review, inputs from colleagues of the department and experts in the area. The proforma consisted of demographic details of the patient, history of disease along with the probable risk factors and findings of the clinical examination of the patients. It took around 15-20 minutes to interview each parent/ caregiver and take measurements in the child. The proforma was pretested and modifications were made as per need.

Ethical clearance to conduct this study was taken from the Institutional Review Committee of Kathmandu Medical College. Prior to data collection, written informed consent was taken from the parents/ caregivers of each respondent. The interview was conducted separately with each parent/ caregiver and they were given full right to withdraw from the study any time without fear or explanation. Confidentiality was maintained throughout the study and the obtained data was used for research purpose only.

Data was checked for completeness and accuracy after collection and before entry. It was edited, organized and coded using Statistical Package for Social Sciences (SPSS) version 20 . The collected data was analyzed using descriptive statistics like frequency, percentage, mean, median and standard deviation.

\section{RESULTS}

A total of 69 patients labeled with the diagnosis of asthma were enrolled during the study period. The patients ranged from 2 years of age to 13 years of age with a mean age of 6.44 \pm 3.36 years. Males comprised of majority $(68 \%)$ of patients.

There was a wide variation in the duration of symptoms from few days to years with median duration of symptoms being 21 days. Cough was the most common symptoms followed by shortness of breath and noisy breathing (Figure.1).

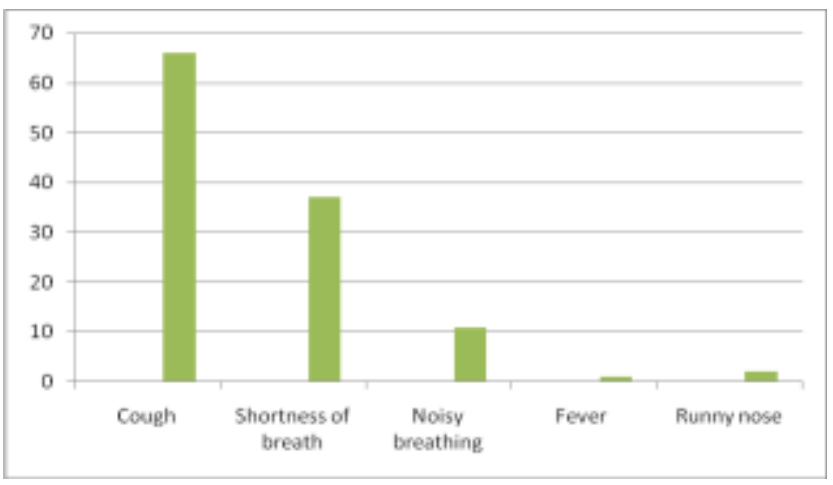

Figure 1 : Frequency of presenting symptoms of the patients $(n=69)$ 
Enrolled patients were born with a mean birth weight of $2.99 \pm 0.59 \mathrm{~kg}$ and a median gestational age of 38 weeks. There were 5 preterm babies in the study while 13 babies were low birth weight. More than half (59.4\%) of the deliveries were vaginal while the rest were caesarean section deliveries. Only around $29 \%$ of deliveries needed admission during infancy for any respiratory illness.

On questioning for risk factors of asthma, it was found that $65.2 \%$ of the patients had a physician diagnosed allergic rhinitis. However, only around $5 \%$ had a history suggestive of atopic dermatitis. Around $52.2 \%$ of the patients had a family history of atopy. Similary, one fifth of the patients reported of passive smoking at home. Majority of the caregivers (56.5\%) complained of mite and cockroach problems at home. Only 9 (13\%) patients had a pet at home. An astounding 94\% of caregivers reported having given some form of asthma medications viz. salbutamol and/or steroid to their children during episodes of cold. Apart from episodes of cold, almost $85 \%$ of patients had history of cough and shortness of breath (Table 1).

$\begin{array}{lcc}\begin{array}{l}\text { Table 1: Frequency of risk factors present in the patients } \\ \text { Risk Factor }\end{array} & \text { Frequency }(\mathrm{n}=69) & \text { Percentage } \\ \text { History of atopy } & 45 & 65 \\ \text { Family history of atopy } & 36 & 52 \\ \text { Passive smoking } & 15 & 21 \\ \text { Mites/Cockroaches at home } & 39 & 56 \\ \text { Pets at home } & 9 & 13 \\ \text { History of asthma medication use } & 65 & 94 \\ \text { Shortness of breath without viral } & & \\ \text { URI } & 58 & 84 \\ \text { Low birth weight } & 13 & 19\end{array}$

On anthropometric measurement of children, the mean weight of children was $22.59 \pm 9.38 \mathrm{~kg}$ while mean height was $116.79 \pm 16.39 \mathrm{~cm}$. Mean body mass index (BMI) calculated was $15.97 \pm 3.7 \mathrm{~kg} / \mathrm{m}^{2}$.

Examination of the patients revealed wheeze in $95.7 \%$ of the patients while crepitations were noticed in only $3(4.3 \%)$ patients. Prolonged expiration was a finding on auscultation in 51 (73.9\%) patients. Hypoxia was noted in only 4 (5.8\%) patients.

Most of the patients (75.4\%) enrolled in the study were labeled as mild persistent asthma followed by intermittent asthma in $18.8 \%$ and moderate persistent asthma in $5.8 \%$ (Figure 2).

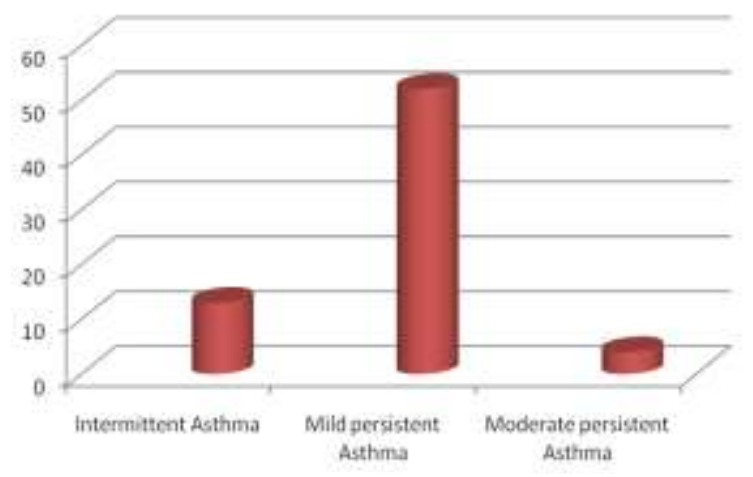

Figure 2 : Frequency of asthma according to severity $(n=69)$

\section{DISCUSSION}

Asthma has been the most common chronic respiratory illness in children worldwide. Multiple studies have been carried out worldwide to elucidate different risk factors for development of asthma.

Studies across the globe have reported that asthma is more prevalent in younger children as compared to older children. The mean age of children in this study was 6.64 years. This was similar to the results in other studies as well. ${ }^{5-7}$ Similar study carried out by Jain et al has also reported the age group 6-9 years as the most prevalent age group for asthma. ${ }^{7,8}$ However, in a study done in Kathmandu valley, the mean age of the patient was found to be much higher at 14.1 years.

Regarding gender specificity of the disease, there have been conflicting results. This study showed $68 \%$ of the patients to be boys. Similar to this finding, multiple studies have reported male predominance. ${ }^{5-7,10}$ In contrast, few studies have also shown female preponderance for development of asthma. ${ }^{11,12}$ However, there are studies which have found no significant gender difference in development of asthma. ${ }^{4,8,13}$

Cough and shortness of breath have been found to be the most common presentation of asthma in the present study. Although cough is a very common symptom of asthma, wheezing has been underreported in this study as compared to other studies.

Prematurity has been strongly linked with development of asthma in later life. In this study, only 5 of the patients were born preterm. This is in contrast to studies which have shown significant association of preterm and low birth weight babies with asthma. ${ }^{14,15}$ With better neonatal care and improved survival of preterm neonates, perhaps in due course of time we may find higher number of preterm babies later developing asthma.

Atopy has been a known risk factor for development of asthma. In this study as well, atopic conditions like allergic rhinitis was found to be present in a significant number of asthmatic patients. Similar results have been published from other parts of the world as well. ${ }^{16}$ However, there are studies reporting to the contrary where no significant association was noticed between asthma and allergic rhinitis. $^{13}$

Family history of atopy has been noted in majority of patients in concordance with studies elsewhere as well. ${ }^{7,8,16}$ Pokharel et al however noted no significant differences in prevalence of asthma with regards to family history of atopy. ${ }^{17}$

Passive smoking was found in one fifth of the patients enrolled. This figure may be lower than compared to other studies which have shown significant association between passive smoking and asthma. $5,16,17,18$

Wheezing was the most consistent finding in patients enrolled in the study. This supports the finding elsewhere reporting wheezing as hallmark of asthma., ${ }^{8,19,20}$

In this study, most of the patients were found to have taken asthma medications in the past year which was consistent with findings of other studies as well. ${ }^{13}$ Most of the patients were found to have been given salbutamol and/ or oral steroids by their parent for cough. The large number of 
patients taking these asthma medications may be due to easy availabilty of these drugs over the counter in pharmacies around the country and a lack of felt need of the parents to consult a doctor for a simple ailment like cough.

Most of the children with asthma had mild persistent asthma followed by intermittent and moderate persistent asthma. Similar findings were reported in previous studies. ${ }^{7}$ This study did not report a single case of severe asthma during the study period. However, Hessen et al reported prevalence of severe asthma to be $7.3 \%$ in school going children of Kathmandu in $2003 .{ }^{18}$ This finding may be due to availability of better care now as compared to 15 years ago, thus minimizing the advancement of the disease to severe asthma.

\section{CONCLUSION}

This study tries to elucidate some of the well documented risk factors in the Nepalese setting. The study found asthma to be more prevalent in male population while mild persistent asthma was the most common severity present in the population. The most frequent risk factor for asthma found in the current study was physician diagnosed allergic rhinitis. However some seem to be not so prevalent.

\section{RECOMMENDATIONS}

The rising number of cases of childhood asthma makes a detailed study on possible risk factors for the disease an urgent need. Also, a higher sample size and longer data collection period can be used in upcoming studies. Inferential statistics can be used to find out the association of risk factors with the development of asthma. The study has tried to elucidate the risk factors described in the western literature. Perhaps study of local risk factors like indoor air pollution, overcrowding, etc need to be further evaluated.

\section{LIMITATIONS OF THE STUDY}

The study design, samples limited to only one institute and duration of study poses some amount of limitation. Also, as a cross-sectional study with descriptive statistics alone, it is not able to draw hard conclusions about the cause for development of the disease.

\section{ACKNOWLEDGEMENT}

To all the patients who made this study possible.

\section{CONFLICT OF INTEREST}

None.

\section{FINANCIAL DISCLOSURE}

None

\section{REFERENCES}

1. National Heart, Lung, and Blood Institute $\mathrm{NI}$ of H. International Consensus Report on Diagnosis and Treatment of Asthma. European Respiratory Journal 1992;5, PMID: 1612163

2. Global Initiative for Asthma (GINA). Global Strategy For Asthma Management and Prevention. 2016. 1-147 p.

3. Asher I, Pearce N. Global burden of asthma among children. Int J Tuberc Lung Dis. 2014: 1;18(11):1269-78. DOI: 10.5588/ijtld. 14.0170

4. Buelo A, McLean S, Julious S, Flores-Kim J, Bush A, Henderson J, et al. At-risk children with asthma (ARC): a systematic review. Thorax. 2018:5;thoraxjnl-2017-210939.DOI: 10.1136/thoraxjnl-2017-210939

5. Litonjua AA, Weiss ST. Risk factors for asthma. 2015: 538-47. PMID:12921231

6. Baltrus P, Xu J, Immergluck L, Gaglioti A, Adesokan A, Rust G. Individual and county level predictors of asthma related emergency department visits among children on Medicaid: A multilevel approach. J Asthma. 2017: 2;54(1):53-61. DOI: 10.1080/02770903.2016.1196367

7. Manandhar K, Bajracharya BL, Dhakal S, Shrestha M. Morbidity pattern of children with asthma: a prospective study. Kathmandu Univ Med J(KUMJ). 4(3):324-8.PMID: 18603927

8. Jain $A$, Vinod Bhat $H$, Acharya D. Prevalence of bronchial asthma in rural Indian children: A cross sectional study from South India. Indian J Pediatr. 2010;77(1):31-5.DOI: 10.1007/s12098-009-0308-6

9. Melsom T, Brinch L, Hessen JO, Schei MA, Kolstrup N, Jacobsen BK, et al. Asthma and indoor environment in Nepal. Thorax. 2001;56:477-81. DOI: 10.1136/thorax.56.6.477

10. Stingone JA, Claudio L. Asthma and Enrollment in Special Education Among Urban Schoolchildren. Am J Public Health. 2006;96(9): 1593-8. DOI: 10.2105/AJPH.2005.075887

11. Quinto KB, Zuraw BL, Poon K-YT, Chen W, Schatz M, Christiansen SC. The association of obesity and asthma severity and control in children. J Allergy Clin Immunol. 2011;128(5):964-9.DOI: 10.1016/ j.jaci.2011.06.031
12. Rust G, Zhang S, Reynolds J. Inhaled corticosteroid adherence and emergency department utilization among Medicaid-enrolled children with asthma. J Asthma. 2013;50(7):769-75.DOI: 10.3109/ 02770903.2013.799687

13. Engelkes M, Janssens HM, de Ridder MAJ, Sturkenboom MCJM, de Jongste JC, Verhamme KMC. Real life data on incidence and risk factors of severe asthma exacerbations in children in primary care. Respir Med. 2016;119:48-54.DOI: 10.1016/j.rmed.2016.08.016

14. Harju M, Keski-Nisula L, Georgiadis L, Räisänen S, Gissler M, Heinonen $\mathrm{S}$. The burden of childhood asthma and late preterm and early term births. J Pediatr. 201;164(2):295-9.e1.DOI: 10.1016/j.jpeds. 2013. 09.057

15. Sonnenschein-van der Voort AMM, Arends LR, de Jongste JC, AnnesiMaesano I, Arshad SH, Barros H, et al. Preterm birth, infant weight gain, and childhood asthma risk: a meta-analysis of 147,000 European children. J Allergy Clin Immunol. 2014 ;133(5):1317-29. DOI: 10.1016/j.jaci.2013.12.1082

16. Federico MJ, Hoch HE, Anderson WC, Spahn JD, Szefler SJ. Asthma Management for Children: Risk Identification and Prevention. Adv Pediatr. 2016;63(1):103-26.DOI: 10.1016/j.yapd.2016.04.010

17. Pokharel PK, Kabra SK, Kapoor SK, Pandey RM. Risk factors associated with bronchial asthma in school going children of rural Haryana. Indian J Pediatr. 2001;68(2):103-6. PMID: 18604079

18. Hessen JO, Schei M, Pandey MR, Smith KR. Prevalence And Risk Factors For Asthma In Nepal. Epidemiology. 2003;14 (Supplement): S123. DOI: 10.1097/00001648-200309001-00300

19. Hill RA, Standen P J, Tattersfield A E. Asthma, wheezing, and school absence in primary schools. Arch Dis Child. 1989;64:246-51.DOI: 10.1136/adc.64.2.246

20. Chhabra SK, Gupta CK, Chhabra P, Rajpal S. Risk factors for development of bronchial asthma in children in Delhi. Ann Allergy, Asthma Immunol. 1999;83(5):385-90.DOI: 10.1016/S1081-1206(10) 62835-9 